\title{
Grounding System Modelling and Its Impact on Computational Refunding Analysis for Equipment Damages
}

\author{
I. N. Gondim ${ }^{1}$, J. C. de Oliveira ${ }^{1}$, C. E. Tavares ${ }^{1}$, J. A. F. Barbosa Jr. ${ }^{1}$ and M. V. B. Mendonça ${ }^{2}$ \\ ${ }^{1}$ Faculty of Electrical Engineering \\ UFU, Federal University of Uberlândia \\ Campus Santa Mônica - Av. João Naves de Ávila, 2121 - Bloco 3N - Uberlândia (Brazil) \\ Phone/Fax number: +55 343239 4733/+55 343239 4704, e-mail: gondim.isaque@gmail.com, jcoliveira@ufu.br, \\ carlosetavares@yahoo.com.br, johnareis@gmail.com \\ ${ }^{2}$ Department of Electrical Engineering - UnB, University of Brasília, email: Marcus@ene.unb.br
}

\begin{abstract}
This paper is aimed at presenting the computational results of the influence of the grounding systems representation in the refunding request analysis of equipment damages due to distribution system disturbances. The assessments include representation of grounding systems with linear and nonlinear parameters to produce a better representation of the overall electrical system at abnormal operating conditions. The model is included in a existing computational programme to deal with the subject of establishing a relationship between system occurrences, dielectric and thermal impacts on equipments and their withstand capabilities. This paper proposed grounding representation is based on a non-linear approach combining method already published in the literature. The methodology is then implemented in a computational tool facility to deal with the mentioned subject and the new software version is then used to evaluate practical situations. Comparisons between results derived from a typical distribution disturbance using simple ground modelling and the new proposition are carried out so as to highlight the importance of a more realistic modelling for the overall electrical complex.
\end{abstract}

\section{Key words}

Power quality, refunding request for damages, grounding systems, case studies.

\section{Introduction}

The changes occurred on the power system at the last years associated with the population knowledge about its consumer rights as well the rising use of devices more sensible to the power quality deviation [1] reveal that researches about "Refunding Request for Damages" (RRD) have been greatly increasing in the whole world.

Actuality, the occurrence of natural phenomenon and the operation of protection devices may affect several industrial, commercial and residential consumers' equipment [2]. This situation may jeopardize the physical appliance integrity and these concerns are especially true for new technology devices [3], [4], [5]. This situation has provoked an appreciable growth of compensation demands for electrical equipment supposedly damaged because of a non-ideal voltage supply from the utility. The question becomes more relevant when one considers the amount of financial resources involved in the matter.

Thus, it is important the development of mechanisms to establish a systematized procedure, based in science and technology, which yields to an impartial decision about the judgments. In this way there are different possibilities to analyse and provide a final report about a given occurrence. One of this consists in using a computational strategy to evaluate the relationship between typical distribution system disturbances and their propagation up to the end consumer.

Aiming at accomplishing this goal arises the matter of obtaining a software to simulate a given abnormal operating condition, its impact on consumer equipments so as to provide means to answer the request under analysis. To achieve such tool it becomes necessary to implement computational models that are appropriate to represent the power grids from any busbar until the end user and that is capable of reproducing disturbances and correctly model consumer equipments. This development has been fully described in [6]. This reference points out the final product called by APR software. The computational base utilized is the ATP (Alternative Transients Program) linked to other facilities developed throughout the MODELS routine. Although the advances offered by this product, it is still presented as a tool worthy of further improvements to match the power network and consumer needs.

When establishing the relationship between causes and effects, the ground systems modelling arise as a critical aspect. As a matter of fact, its representation has a great influence on the results. The literature and the experience have shown that some disturbances which would be considered to a wide range of RRD's applications may be associated with currents circulating throughout the grounding systems. Therefore, this can cause potential differences between distinct grounding systems, and also, between neutral point and remote earths. This is the situation that occurs, for example, during the incidence of lightning strikes and asymmetric faults.

Thus, a correct representation of the grounding systems cannot be ignored or treated as elementary models, such as a simple equivalent resistance. The inclusion of such effects must be priority to a strategy, pondering the consistency between simplicity and objectivity, so that the influence of these factors can be properly represented in order to match the simulation results with those from the reality.

In this way, this paper aims to present a summary of existing proposals for grounding systems modelling and a strategy towards the evaluation of the disturbance responses with different models. The studies to be described are associated with a real case of a refunding request for damages Thus this paper involves representations of earth systems with the linear and nonlinear parameters. Besides the evaluation of the 
existing proposals, this work offers a grounding model derived from the combination of the mains advantages associated to the two nonlinear models found in the literature [7], [8] and [9].

\section{Grounding Systems Models}

In order to evaluate the performance of grounding systems when they are carrying impulsive and shortcircuit currents, a lot of models of grounding configurations have been developed over the years.

According to [7], the methods used for the studies of grounding systems, and published in the literature, are mainly characterized by analytical and empirical methods, and also by numerical methods. The latter are widely used nowadays due to advances in computing.

Additionally, according to [8], representations of the grounding systems can be further divided into types of electrodes with linear or nonlinear parameters, as well as concentrated or distributed. The adoption by using the linear or nonlinear parameters is associated with the current magnitude through the electrode. In general, for the case studies in which occurs the earth ionization it opts for the consideration of non-linear parameters. On the other hand, the selection of concentrated or distributed parameters is linked with the relationship between the frequency drain current and the electrode length. That said, it is evident that models with concentrated parameters are acceptable when the wavelength of the currents that goes through is much greater than the electrode length.

The use of non-linear parameters to represent the behaviour of grounding systems is linked to the fact that, upon the occurrence of phenomena that cause the circulation of a high current through the electrode, the electric field in the areas around it can reach critical levels that can result in partial discharges. This part of the soil corresponds to the ionized zone, and usually confined to areas surrounding the electrode. Therefore, this part of the land is characterized by presenting a conductance higher than own it. The models designed until the present time, under non-linear parameters aim principally the grounding systems analysis carrying impulsive current.

In [9], the authors developed a dynamic model to represent earth systems through the elements with concentrated parameters for the establishment of impulsive currents in the electrodes. This proposal considers situations, which high currents result in paths of soil breakdown and on its surface. Also according to this study, it was noted the formation of discharges from the point of incidence of the current pulse. This model, which is characterized by its nonlinearity intrinsic to the behaviour of earth resistance, constitutes itself as the basis for the studies highlighted in this paper in order to represent the effects coupled with the soil ionization.

Following are presented the aspects concerning the representation of grounding systems employing nonlinear parameters.

\section{Computational Implementation Through ATP}

Making use of mathematical equations described in [9], the computational implementation was conducted in the simulator ATP used to represent the grounding systems through non-linear parameters, using for this, the programming language MODELS. It is noteworthy that a change was made in the area of equipotential surface formed around the electrode, which means considering, instead of a simply hemispherical surface, an area equivalent to the sum of two surfaces: a hemispherical and another cylindrical, aiming to characterize the geometry of a ground rod. This characteristic is described in [10]. The resulting geometry of equipotential surfaces and soil regions considered for the characterization of the model are illustrated in Fig. 1.

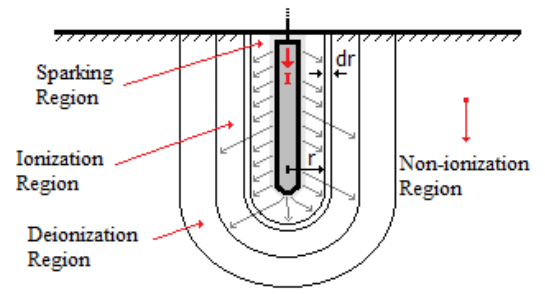

Fig 1. Nonlinear model for concentrated grounding systems.

This model describes the variation of soil resistivity, $\rho$, when subjected to impulsive currents through an exponential behaviour. Additionally, the grounding resistance, taking into account an electrode with length 1 , is calculated on the basis of differential surface with length "dr" (Fig. 1). The expression (1) is used for this purpose. Further details on the procedures of calculations used to characterize the model can be found in [11].

$$
d R=\frac{\rho \cdot d r}{2 \pi \cdot r^{2}+2 \pi \cdot r \cdot l}
$$

To evaluate the computational results, researches employing the experimental information contained in [9] were then used.

\section{A. Experimental Results}

To obtain the experimental results, the authors used a ground rod and soil characteristics presented in Table I.

Table I. - Grounding Characteristics Used in Experiments

\begin{tabular}{|c|c|c|}
\hline $\begin{array}{c}\text { SOIL } \\
\text { RESISTIVITY } \\
{[\Omega \cdot \mathrm{m}]}\end{array}$ & $\begin{array}{c}\text { ELECTRODE } \\
\text { RADIUS } \\
{[\mathrm{mm}]}\end{array}$ & $\begin{array}{c}\text { ELECTRODE } \\
\text { LENGTH } \\
{[\mathrm{m}]}\end{array}$ \\
\hline 270 & 6,35 & 0,61 \\
\hline
\end{tabular}

The imposition of a current signal, coming from the application of a voltage across a LC series arrangement, it was obtained the results for the voltage and current shown in Fig. 2. This current and voltage are derived from measurements. Fig. 3 describes the resistance variation of grounding system as function of current. 


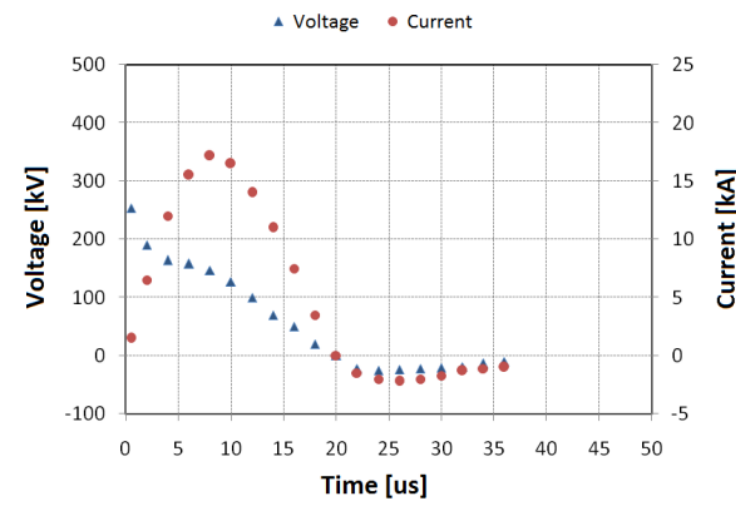

Fig 2. Experimental waveforms of resulting voltage and current imposed on the earth system.

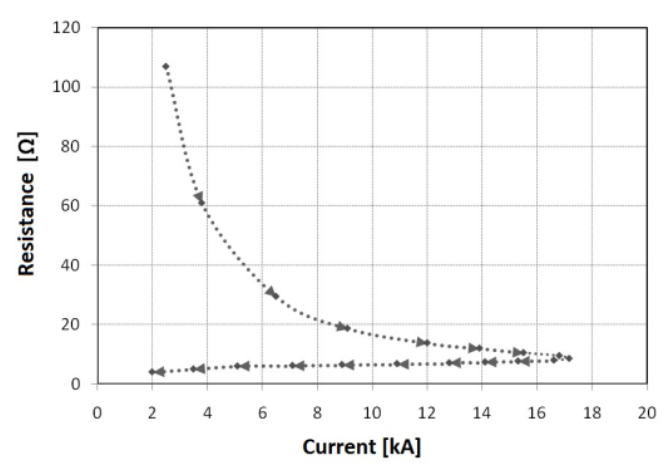

Fig 3. Resistance as function of current - experimental result.

\section{B. Computational Results}

The computational reproduction of a current signal similar to that shown experimentally was possible from using the "Pointlist" function, provided by the MODELS of ATP. This function allows the input of a waveform and its application in this case, especially in resistance with a nonlinear behaviour.

After implementation and parameterization of the model and, once inserted the change already noted earlier, Fig. 4 shows the waveforms of voltage and current in the electrode obtained by simulation. Additionally, Fig. 5 shows the computational behaviour of nonlinear resistance of grounding system.

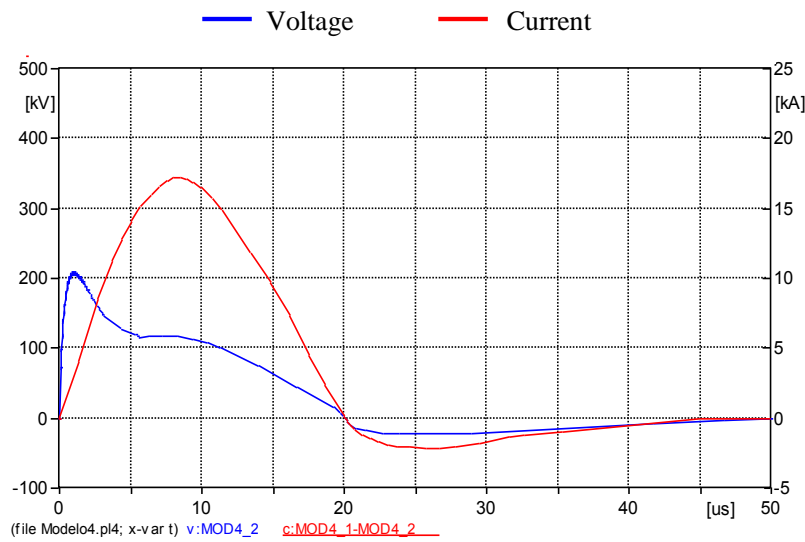

Fig 4. Voltage and current computational waveforms.

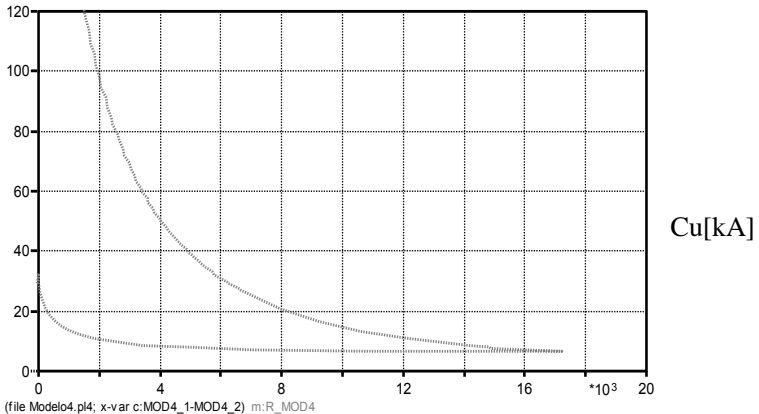

Fig 5. Resistance as function of current - computational result.

From the above it follows that the voltage waveform presented a pattern similar to the experimental result, except the small percentage difference noted in maximum voltage. Table II summarizes previous results and allows an early preview of the modeling performance on the ATP platform.

Table II. - Comparison between Computational and Experimental Results

\begin{tabular}{|c|c|c|}
\cline { 2 - 3 } \multicolumn{1}{c|}{} & Computacional & Experimental \\
\hline Peak voltage $[\mathrm{kV}]$ & 209,1 & 253,3 \\
\hline Peak Current $[\mathrm{kA}]$ & 17,2 & 17,2 \\
\hline $\begin{array}{c}\text { Voltage at the peak } \\
\text { current }[\mathrm{kV}]\end{array}$ & 116,1 & 146,7 \\
\hline $\begin{array}{c}\text { Resistance at the } \\
\text { peak current }[\Omega]\end{array}$ & 6,7 & 8,6 \\
\hline
\end{tabular}

\section{Model Application for a Real Case of Refunding Request for Damages}

To evaluate the influence of modelling grounding systems in the computer analysis of RRD, information of the requests, procedures and final decisions were obtained from some electric utilities. Among a large set of real cases, was selected a case of refunding request for damage at a microcomputer due to lightning strike. This phenomenon resulted in a operation of automatic circuit recloser in one feeder of the substation that serves the region, where the consumer takes place.

Figure 6 shows the diagram system evaluated in APR. An important point that must be clarified concerns the bus system. The bars represent the five "nodes", which are: phases A, B, C, neutral and ground connection point. At the end of the diagram notes the presence of a representative icon of the consumer's residence, where is the equipment under analysis. According to information from consumers, the microcomputer was powered at 127 $\mathrm{V}$, i.e, between phase and neutral, according power supply configuration.

All components of the distribution system were parameterized inside the typical models library provided by ATP simulator, with some special features added for the desired applications, such as the microcomputer. The details and validation about this procedure can be found in [12].

The lightning strike parameters applied to the analysed system were fitted to the current waveform standard with $8 / 20 \mu$ s. It was adopted the incidence of $10 \mathrm{KA}$ value over 
the medium voltage overhead line (see this point at Fig. 6)

The distribution network grounding systems are divided into two groups: one represents the substation grounding grid and the other the surge arresters grounding electrodes (rods), neutral and consumer unit protective conductor. The substation grounding grid is set by an equivalent resistance of $0.6 \Omega$. For the grounding rods placed in the distribution network, it was used typical parameters based on electrode with 3 meters length and $5 / 8$ inch diameter. The soil characterization around these rods, was setup with resistivity of $100 \Omega \cdot \mathrm{m}$.

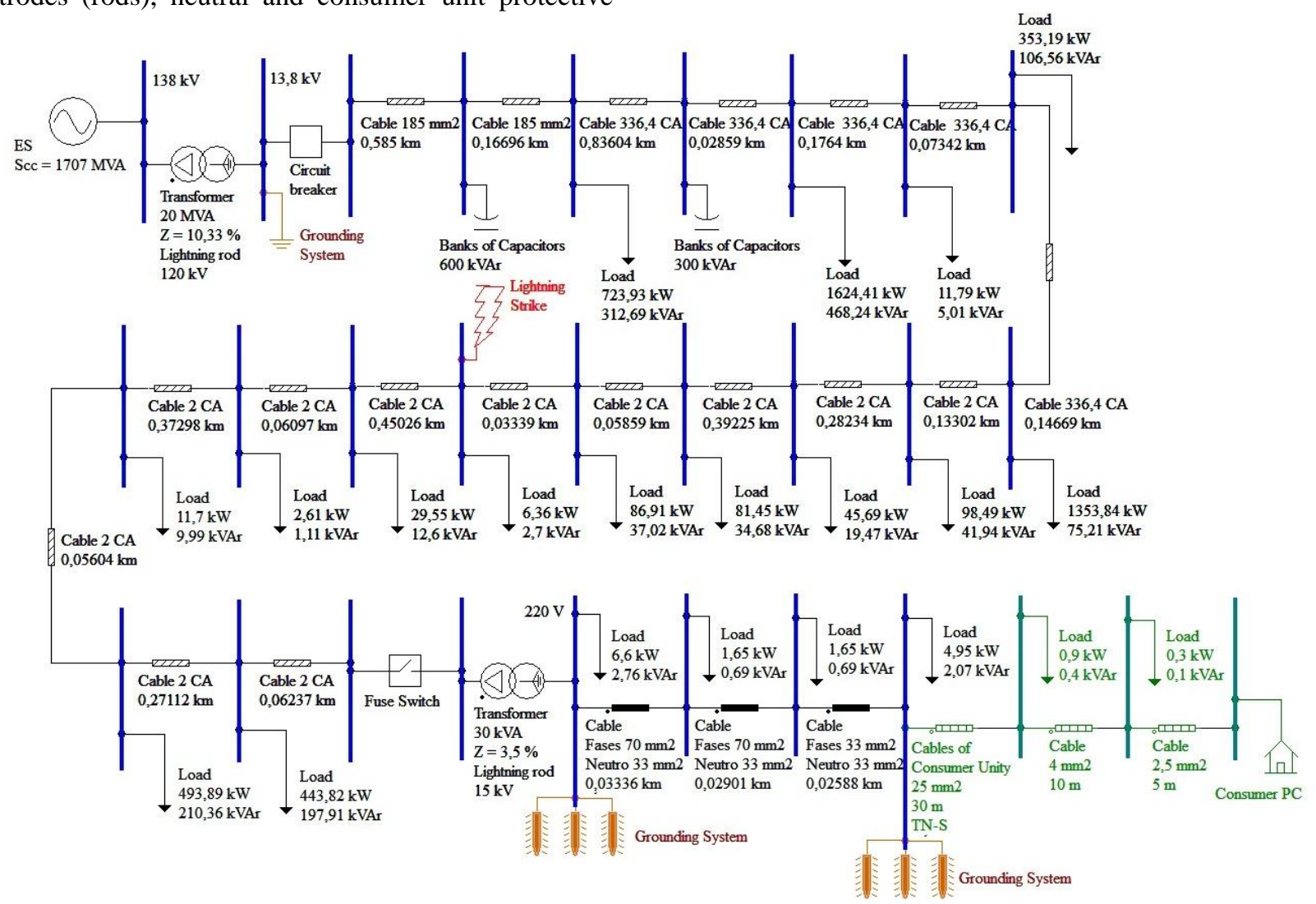

Fig. 6. Analyzed System.

In order to expose clearly the results, they were divided into the following parts, according to the grounding systems representation used:

- Case 1: Linear model (constant resistance) for grounding systems;

- $\quad$ Case 2: Non-linear model (variable resistor) to ground systems, as described previously;

After configuration, parameterization and electrical system simulation with the characteristics of the occurrence causing the refunding request for damages, the results are shown in sequence.

\section{A. Case 1: Linear model for grounding systems}

Figs. 7 and 8 show respectively the voltage and current waveforms in the consumer unit where is connected the microcomputer under disturbance. The voltage waveforms illustrated in figure are computed for a remote reference. The peak voltage between phase and neutral was approximately $20 \mathrm{kV}$. The maximum value displayed for the current during the transient was approximately $80 \mathrm{~A}$.

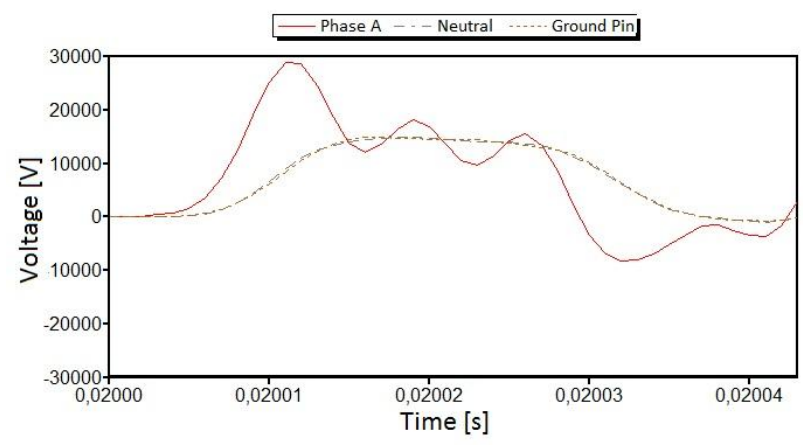

Fig. 7. Transient voltage waveform in microcomputer input under lightning strike - Case 1.

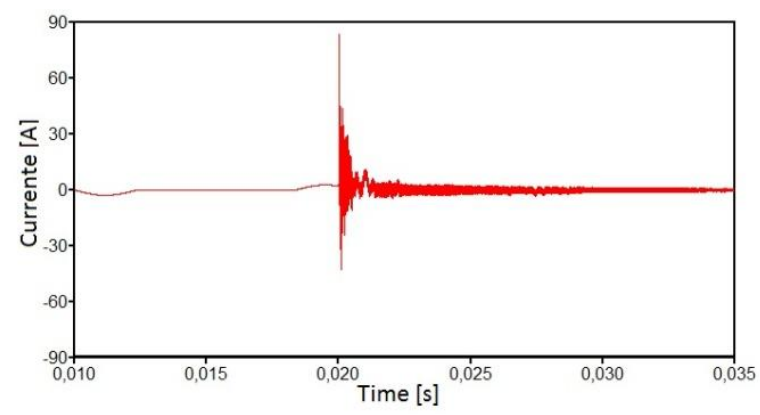

Fig. 8. Transient current waveform in microcomputer input under lightning strike - Case 1.

To convert the results observed in the equipment input by indicative curves of the voltage and current solicitation, it 
was used a computational procedure for calculating, which discretize the disturbance period and calculate, for each instant, indicators that represent the voltage and current cumulative effect. These indicators are calculated by the expressions (1) and (2), which correspond respectively to voltage and current solicitation. More information about this calculation method can be found in [13].

$$
V_{k}=\sqrt{\frac{\sum_{i=1}^{n} V_{i}^{2}}{n}}
$$

Where:

- $\quad V_{k}$ - dielectric value for any instant of time;

- $V_{i}$ - voltage instantaneous value for any instant of time;

- $n$ - number of samples or quantity of time intervals processed.

$$
I_{k}=\sqrt{\frac{\sum_{i=1}^{n} I_{i}^{2}}{n}}
$$

Where:

- $\quad I_{k}$ - thermal stress value for any instant of time;

- $I_{i}$ - current instantaneous value for any instant of time;

- $n$ - number of samples or quantity of time intervals processed.

These expressions allow phase-neutral voltage and current conversion at the equipment input expressed in thermal and dielectric stresses curves. These one, as compared to their respective withstand capability levels, offers guidelines for a technical opinion the probably equipment damage connected to the feeder where the phenomenon occurred.

Using this methodology in comparison with the microcomputer withstand capability limits found in [3] [4], [14], the Figs. 9 and 10 are obtained. At can be seen if the phenomenon occurred in the network leads to a stress under the corresponding withstand capability curve, then an operating condition without the probabilistic damage risk could be occurred. However, if the disturbance has generated stresses higher than the withstand capability, it would be an indicator for the possibility of damage to the product under investigation, thus justifying the refund for damage.

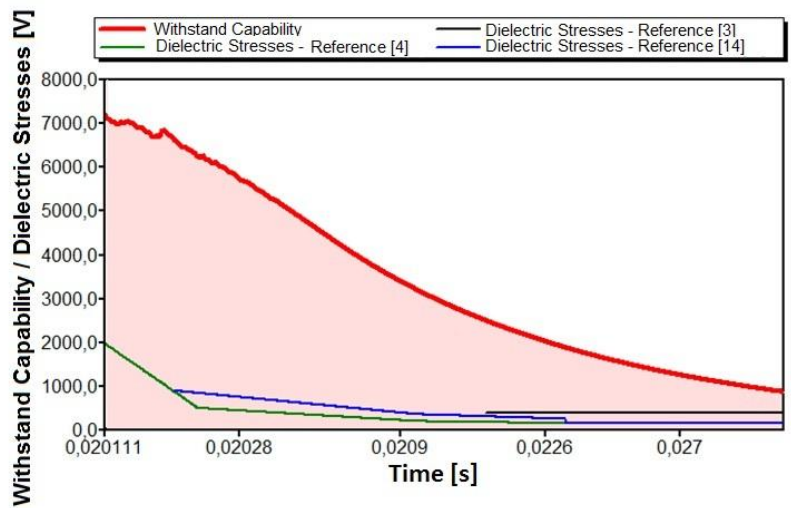

Fig. 9. Dielectric stresses versus withstand capability of the microcomputer under a lightning strike - Case 1.

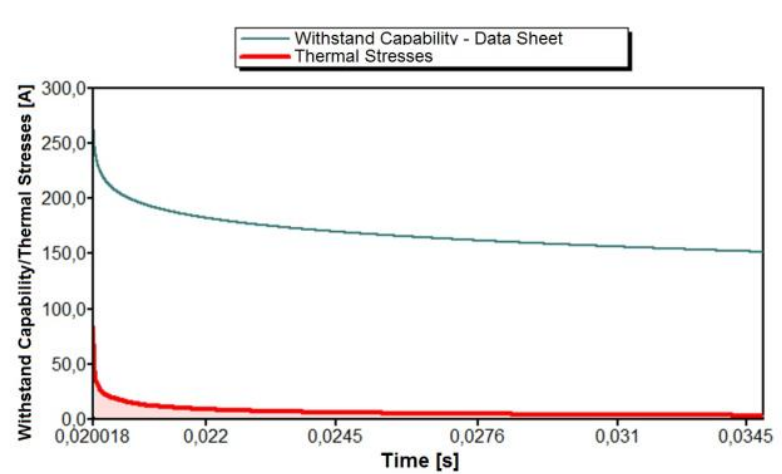

Fig 10. Thermal stresses versus withstand capability of the microcomputer under a lightning strike - Case 1.1 .

The results are clearly enough to highlight that the applied impulse will not be tolerated by the equipment. This violation occurred for the dielectric withstand capability. The figures also show that the thermal limit has not been reached.

\section{B. Case 2: Non-linear model for grounding systems}

Figs. 11 and 12 show respectively the voltage and current waveforms for the same feeder previously submitted to the lightning strike. The phase-to-neutral voltage peak in this situation was $14.7 \mathrm{kV}$, lower than that mentioned in the previous situation. Consequently, the maximum current during the transient reached a lower value of approximately $55 \mathrm{~A}$.

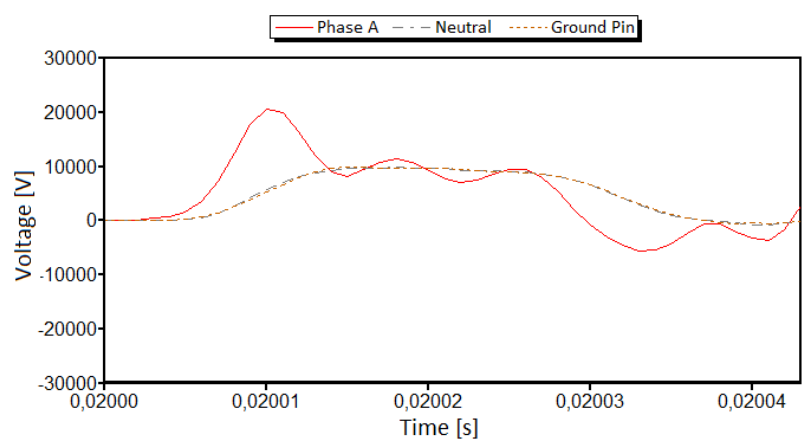

Fig 11. Transient voltage waveforms in the microcomputer input under a lightning strike - Case 2 .

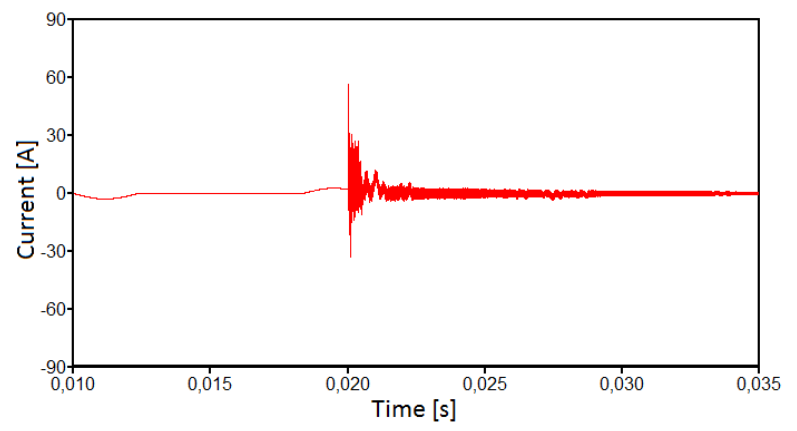

Fig 12. Transient current waveform in the microcomputer input under a lightning strike - Case 2.

Comparing Fig. 11 to Fig. 7 it's clear that the ground ionization causes attenuation in the voltage propagated to the consumer unit. This fact is associated with the earth resistance reduction caused by the phenomenon previously mentioned. This result demonstrates the importance of taking into account this effect in the refunding requests analysis.

The thermal and dielectric stresses imposed to the equipment and their respectively withstand capability curves are represented in Figs. 13 and 14. 


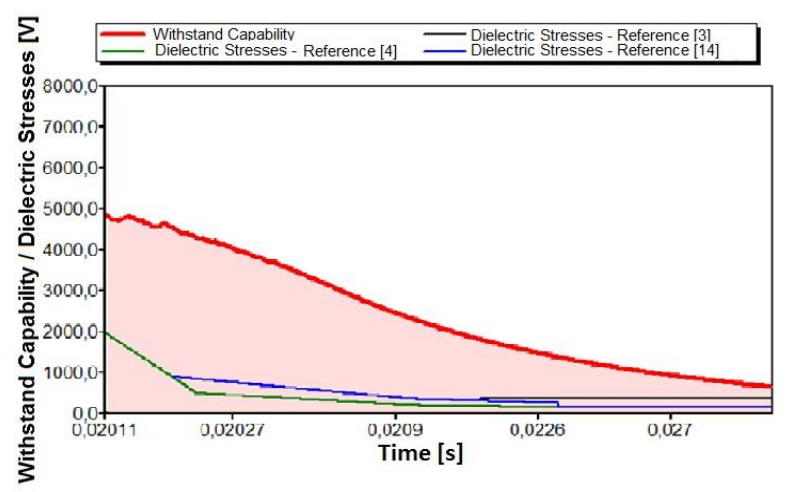

Fig. 13. Dielectric stresses versus withstand capability of the microcomputer under a lightning strike - Case 2.

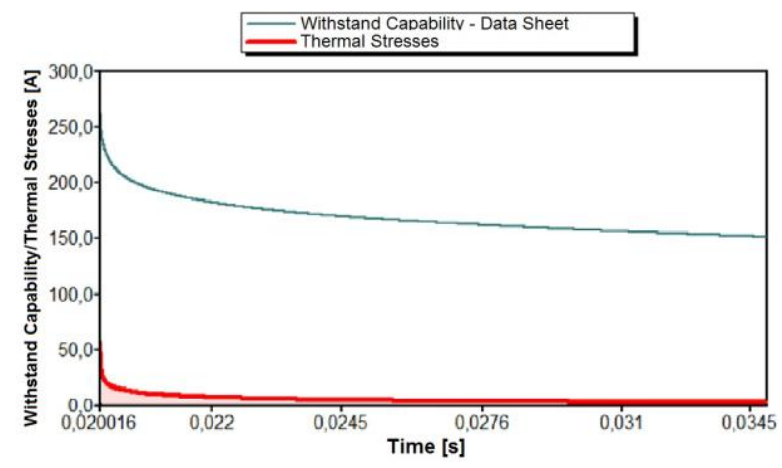

Fig. 14. Thermal stress versus withstand capability of the microcomputer under a lightning strike - Case 2

Again, the applied impulse will not be tolerated by the equipment. This violation occurred for the dielectric withstand capability. However, it must be highlighted that the values found for the voltage were lower. Therefore, the grounding representation has to be taking into account to reach better results. The figures also show that the thermal limit has not been reached.

\section{Conclusions}

This work has been involved with investigations associated with the earth systems modelling and its influence on the final reports about equipment damage refunding analysis. It has been shown that at lightning strike occurrence, this may result in the formation of soil regions that produce lower resistivity lower due to the ionization phenomenon around the grounding electrodes. If this condition occurs, the grounding representation by linear model, although its simplicity, indicates great disadvantages and strong effects on the final voltage and current results. Moreover, the model that includes nonlinear parameters, allowing the inclusion of the previous phenomena, is linked with equations, information and complex parameters that are quite difficult to be obtained. This has motivated the idea of a ground representation here proposed. The advantages of this is given by a combination of a good response to disturbances and the need for more simple data.

It has been demonstrated that the use of a more appropriate representations has produced significant reductions in the voltage and current levels at the equipment input. This fact is relevant to the analysis process because it can mitigate transient overvoltage and overcurrent. The investigations have revealed that a given disturbance with linear ground representation may justify a claimed equipment damage and that, by simple changing of the grounding modelling, the same disturbance would not be able to produce the same effect.

\section{Acknowledgement}

The authors acknowledge the financial support received from Brazilian Councils FAPEMIG, CAPES and CNPq for the doctorate and master scholarship which resulted in this paper.

\section{References}

[1] R. C. Dugan, M. F. McGranaghan, S. Santoso, H. W. Beaty, Electrical Power Systems Quality, $2^{\mathrm{a}}$ ed., New York: McGrawHill, 2003.

[2] M. H. J. Bollen, Understanding Power Quality Problems: Voltage Sags and Interruptions, Piscataway: IEEE Press, 2000.

[3] H. R. P. M. Oliveira, N. C. Jesus, M. L. B. Martinez, "Avaliação do Desempenho de Equipamentos Eletrodomésticos Durante Ensaios de Sobretensões", XVIII SNPTEE Seminário Nacional de Produção e Transmissão de Energia Elétrica, Curitiba/PR, Brasil, Outubro de 2005.

[4] M. D. Teixeira, R. L. Araújo, L. M. Ardjomand, A. R. Aoki, N. S. R. Quoirin, I. Wunderlich, "Acceptable Power Quality Limits to Avoid Damages in Appliances", WSEAS Trans. on Circuits and Systems, vol. 4, Maio de 2005.

[5] A. S. Jucá, "Avaliação do Relacionamento entre Consumidores e Concessionárias na Solução de Conflitos por Danos Elétricos: Proposta de Adequação", Tese de Doutorado em Engenharia Elétrica, Escola Politécnica da Universidade de São Paulo, USP, 2003.

[6] C. E. Tavares, M. V. B. Mendonça, J. C. de Oliveira, D. A. de Andrade, E. Flach, "A Computational Approach for Consumers Refunding Analysis Due to Equipment Damages", 2008 IEEE PES Transmission \& Distribution Latin America Conference and Exposition, Bogotá, Colômbia.

[7] L. Gonçalves Jr., "Estudo Teórico-experimental do Comportamento de Sistemas de Aterramento Percorridos por Correntes Impulsivas", Tese de Doutorado em Engenharia Elétrica, Escola de Engenharia de São Carlos da Universidade de São Paulo, USP, 2007.

[8] F. J. T. Teixeira, M. R. Cordeiro, F. O. Resende, A. C. S. M. Moura, "Aplicação do EMTP-ATP ao Estudo Comportamental dos Eléctrodos de Terra em Sistemas Eléctricos de Energia Utilização de Diversos Modelos Bibliográficos", Revista Iberoamericana del ATP, Abril de 2002.

[9] J. Wang, A. C. Liew, M. Darveniza, "Extension of Dynamic Model of Impulse Behavior of Concentrated Grounds at High Currents", IEEE Transactions on Power Delivery, vol. 20, Julho de 2005.

[10] A. C. Liew, M. Darveniza, "Dynamic Model of Impulse Characteristics of Concentrated Earths" Proc. IEE, vol. 121, N 2, págs. 123-135, Fevereiro de 1974.

[11] M. V. B. Mendonça, "Contribuições ao Processo Computacional para Análise de Pedidos de Indenização por Danos em Equipamentos Elétricos", Tese de Doutorado em Engenharia Elétrica, Universidade Federal de Uberlândia, UFU, 2010.

[12] M. V. B. Mendonça, C. E. Tavares, I. Gondim, J. C. Oliveira, A. C. Delaiba, K. D. Rodrigues, "Modelagem de Equipamentos Eletroeletrônicos Utilizando Fontes Lineares e Chaveadas sob Condições Não Ideais de Alimentação na Plataforma ATP", VII CBQEE - Conferência Brasileira sobre Qualidade da Energia Elétrica, Santos/SP, Brasil, Agosto de 2007.

[13] C. E. Tavares, J. C. de Oliveira, M. V. B. Mendonça, A. C. Delaiba, R. M. T. Silva, "An Approach for Consumers Refunding Analysis Associated to Voltage Disturbances and Equipment Damages", Revista Eletrônica de Potência SOBRAEP, vol. 13, No 1 , Fevereiro de 2008

[14] ITI (CBEMA) Curve Application Note. Disponível online em: "http://www.itic.org/archives/iticurv.pdf", acessado em Janeiro de 2007. 